\title{
Clinical features contributing to the sit-to-stand transfer in people with Parkinson's disease: a systematic review
}

\author{
Charmaine Pearl Da Cunha, Pratiksha Tilak Rao and Suruliraj Karthikbabu* (0)
}

\begin{abstract}
Introduction: The aim of this systematic review is to present the existing literature on the clinical motor, and nonmotor factors contributing to sit-to-stand transfer in individuals with Parkinson's disease.

Data synthesis: Five databases (PubMed, PEDro, Cochrane, SCOPUS, and Ovid) were searched for literature on the contributing factors to sit-to-stand performance in Parkinson's disease. A quality check of these observational studies was done using the 'strengthening the reporting of observational studies in epidemiology' (STROBE) statement and the tool of the 'National Heart, Lung, and Blood Institute' (NHLBI). Descriptive and quantitative data were extracted and compiled, and a meta-analysis was performed to compute the standardised mean difference.

Results: Thirteen studies were selected; a majority of them provided a high-to-moderate level of evidence. Ten were cross-sectional, while the other three were case-control studies. Collectively, individuals with Parkinson's disease had a prolonged transfer time than those of age-matched healthy peers, particularly from peak horizontal velocity phase to seat-off phase, implying bradykinesia. A reduction in peak and rate to peak joint torques was also related to the decreased pace and stability of the sit-to-stand movement in individuals with Parkinson's disease. Additionally, they demonstrated exaggerated trunk flexion as a postural stabilisation strategy, allowing them to maintain and manoeuvre the relative positions of their centre of mass through the transitional phase of the transfer.
\end{abstract}

Conclusion: As per the existing literature, an alteration in strength, overall body bradykinesia, balance, posture, as well as cognition may result in an impaired sit-to-stand transfer in individuals with Parkinson's disease.

Keywords: Cognition, Joint torque, Parkinson's disease, Sit-to-stand, Speed, Strength

\section{Introduction}

Degeneration of the cells in the pars compacta of the nigrostriatal circuit and the diminution of the neurotransmitter dopamine in the basal ganglia are the hallmark of Parkinson's disease (PD) [1, 2]. Current prevalence figures show that PD affects 1-2 individuals per every thousand people, and the prevalence has been increasing with age; affecting $1 \%$ of those above 60 years [3]. The fundamental motor symptoms of PD

\footnotetext{
*Correspondence: karthikbabu78@gmail.com

Department of Physiotherapy, Manipal Hospital, Bangalore campus,

Manipal College of Health Professions, Manipal Academy of Higher Education, Manipal, Karnataka, India
}

are bradykinesia, tremor, rigidity, and postural instability, and the equally debilitating non-motor symptoms are sensory, cognitive, and autonomic dysfunctions [4-6]. These clinical factors of the disease negatively influence movement ability and transfers.

Rising from a chair is one such biomechanically complex transfer task for individuals with PD. Although this task is seemingly simple, most people with PD have difficulty in movement preparation and execution $[7,8]$. A centrally programmed sequence of correctly timed and scaled force generation and anticipatory postural adjustments are critical for sit-to-stand (STS) transfer $[9,10]$. The coordinated trunk and lower limb 
motor control are required during a transition of the body from a broad supporting surface to a relatively narrow one $[11,12]$. Bradykinesia - the prolonged time to initiate, change or arrest a movement-is primarily responsible for the sluggish rising from a chair. During the STS transfer, excessive anterior trunk flexion is adopted to make up for the lack of momentum. They continue to move anteriorly instead of propelling the body vertically during the momentum transfer phase. This prolonged anterior trunk flexion places them at a higher risk of falls. Furthermore, individuals with PD have difficulty in assuming and maintaining an upright posture during the terminal extension phase, secondary to extensor muscle weakness $[9,13]$. They use compensatory motor strategies to make up for the postural instability as well as inadequacy and latency of force generation in the lower extremities [9].

As the disease progresses, the resulting instability causes the once easily performed task to seem formidable [14]. Cognitive impairments appear parallelly as executive dysfunctions wherein the sensory information and the motor planning required to perform mobility tasks are affected $[15,16]$. The reduced steadiness also instils a fear of fall in individuals with PD. Consequently, when a motor task involves a cognitive burden, it predisposes them to added balance issues $[17,18]$. Strength, bradykinesia, balance, posture, and cognition are the factors attributed to STS performance. These various factors contribute to the STS transfer, some more largely than others. The inability to perform this necessary [11], yet straightforward action leads to impaired daily functioning and poor quality of life, possibly advancing to institutionalisation. Bryant et al. [19] showed that inability to getting up from a chair is positively related to restricted daily functional independence and physical inactivity. Therefore, understanding the STS activity in terms of its duration, kinematic and kinetic determinants, and postural stability is imperative to the effective care and rehabilitation of individuals with PD.

Although many studies evaluated the STS performance in $\mathrm{PD}$, there is a dearth in the holistic understanding of the factors contributing to the task. Established authors in the field of movement dysfunction believe that this insight will facilitate better rehabilitation strategies $[9,12,14,20-22]$. No known systematic review have reported the contribution of motor and non-motor factors to the STS performance in individuals with PD. This review aims at presenting an overview of the existing literature on the clinical motor, and non-motor factors contributing to the STS transfer performance in individuals with PD.

\section{Main text (review of literature, results, discussion) Review of literature Literature search}

The five electronic databases (PubMed, PEDro, Cochrane, Scopus, and Ovid) were searched for relevant literature between inception to November 2020. The search was limited to observational studies published in English. $\mathrm{MeSH}$ terms were used to guide the search, and the title and abstracts were screened with keywords based on (1) Parkinson's disease (2) sit to stand (3) motor and nonmotor factors including strength, balance, bradykinesia, posture, rigidity, tremor, muscle ache, cognition, depression, orthostatic hypotension, and sensory symptoms. Snowballing through the reference lists of the included articles was conducted to check for any missed literature in the data search. A tabular account of the database searches and the results obtained from them is provided in the Additional file 1 . The titles and abstracts of the articles identified from these searches were examined by two authors to determine if they met the inclusion criteria. If the two authors could not reach an agreement on inclusion, a third author was consulted, and all the potentially relevant articles were retained at this stage. Furthermore, full-text articles were screened to observe if they met the inclusion criteria and confirm eligibility.

\section{Inclusion and exclusion criteria}

The inclusion criteria for selection of studies were (1) people with PD who were medically stable; (2) able to follow verbal commands; (3) both sexes; (4) stage 1 to 3 in the Hoehn and Yahr scale; (5) on anti-parkinsonian drugs and responsive to the medication; (6) studies that analysed the STS transfer; (7) able to rise from the chair with or without an armrest; (8) articles that included the motor and non-motor symptoms contributing to STS. The exclusion criteria were (1) individuals with preexisting lung disorders; (2) major psychiatric illnesses; (3) diagnosed neurological, musculoskeletal, and cardiovascular diseases that possibly affect their ability to perform the STS task; (4) those who had a joint replacement surgery; (5) juvenile PD.

\section{Study selection and data extraction}

After eligibility screening, we chose a total of 13 observational studies, the majority of them being cross-sectional studies. We performed thorough data extraction to gather the study information such as the author, year of publication, study design, objective, methodology, and conclusion. Each study was dissected to understand the participant determinants such as mean age and range, Hoehn and Yahr grading, UPDRS score, the chronicity of the disease, along with the kinematic and kinetic variables of STS. 


\section{Quality assessment}

The quality of all the included papers was evaluated first using the 'strengthening the reporting of observational studies in epidemiology' (STROBE) statement [23]. This tool evaluates the reporting and design of the selected papers. The various items in the checklist were graded as 'yes', 'no' or 'not applicable' depending on which fits most aptly. The second quality check was done using the quality assessment tool of the National Heart, Lung, and Blood Institute (NHLBI) [24]. The items in this tool were also evaluated using the nominal terms-'yes', 'no', 'not applicable,' 'not reported', or 'cannot determine.' The studies were graded and categorised based upon the NHLBI recommendation into three strata: good, fair and poor.

\section{Data analysis}

The data from the included studies were analysed using Cochrane Review Manager Software 5.4. The quantitative data on two parameters of STS-the duration of the transfer, and peak joint torque during the 'on phase' of dopamine therapy were extracted from the published trials and included in this review. The meta-analysis calculated the standardised mean difference and 95\% confidence interval for these two parameters during STS performance, between those with and without PD. Heterogeneity between studies, overall pooled estimate, and the effect size for each of these parameters were calculated and reported as $I^{2}, p$-value, and $z$, respectively.

\section{Results}

\section{Selection of articles for review}

The search from five databases yielded 7042 studies, of which 5055 were duplicates. The remaining 1987 papers were further checked, and only 33 articles went through full-text screening. Of these, 13 papers were selected for the review (Fig. 1).

\section{Description of the studies}

Thirteen observational studies were included, amongst which 10 were cross-sectional, [11-14, 20, 21, 25-28] and the remaining three were case-control studies [9, $22,29]$. All these studies utilised advanced equipment to assess the STS transfer in laboratory settings. The types of equipment used in most studies were force plates and Optotrack imaging systems. In addition to posturography analysis, three studies used electromyography and two papers tested isometric strength using dynamometer. These studies were conducted across the world, five papers from North America [9, 12, 14, 22, 25], three from Europe [13, 20, 26], three from Asia [11, 27, 29], and two from South America [21, 28]. The authors used convenience sampling in most of the studies. The sample size was an average of 25 participants in each study.

\section{Assessment of study validity (quality assessment and risk of bias)}

The methodological quality of the included articles as evaluated with the STROBE statement and NHLBI tool [23, 24] is presented in Tables 1 and 2. The guidelines facilitated a clear interpretation of the reporting and results of the observational studies, and the scoring criteria were derived from the STROBE "Explanation and Elaboration" document [30]. The NHLBI tool further guided the overall rating of the studies [24]. The overall quality of each paper was rated as good, fair, or poor. Three studies were rated as good $[14,20,22]$, seven studies were rated fair $[9,11-13,21,25,27]$, and the remaining three studies were rated as poor quality $[26,28,29]$.

\section{Participant characteristics}

Thirteen papers included in this review had a total of 234 participants with PD. Their age ranged between 49 and 81 years. Details regarding the characteristics of participants, including their age, disease duration, Hoehn and Yahr grading, and the phase of assessment, are expanded into Table 3. Of these 13 studies, 11 had two groups, one being individuals with $\mathrm{PD}$ and the other comprising healthy older adults $[9,11,13,14,20,25-29]$. Five studies specified the age and gender-matched controls $[9,11,20$, $22,25]$. The 13 articles included in this study addressed five factors, namely the motor domains of strength, bradykinesia, balance and posture, and the non-motor domain of cognition [9, 11-14, 20-22, 25-29]. The kinematic, kinetic, and temporal determinants of these factors during the STS transfer are reported in Table 4.

\section{Outcome measures}

The STS transfer was assessed through posturographic techniques in the majority of the studies. Posturography comprises the use of force platforms to detect movements of the body and therefore evaluating the ground reaction forces. Along with force platforms, the joint torque values were obtained from the data of video analysis. Eight of the included studies combined posturography with video analysis, [9, 11, 13, 14, 21, 22, 28, 29] three studies combined posturography with electromyography $[12,14,28]$, and two combined it with dynamometry [20, 22]. Also, three studies assessed the influence of cognition on STS using trail making test and semantic verbal fluency, Stroop test, and sensory cuing strategies [21, 26, 27].

\section{Clinical motor factors contributing to STS transfer Time taken for STS transfer}

The STS transfer is a fundamental task for many daily activities and the efficiency with which it is performed indicates an individual's level of functional independence 


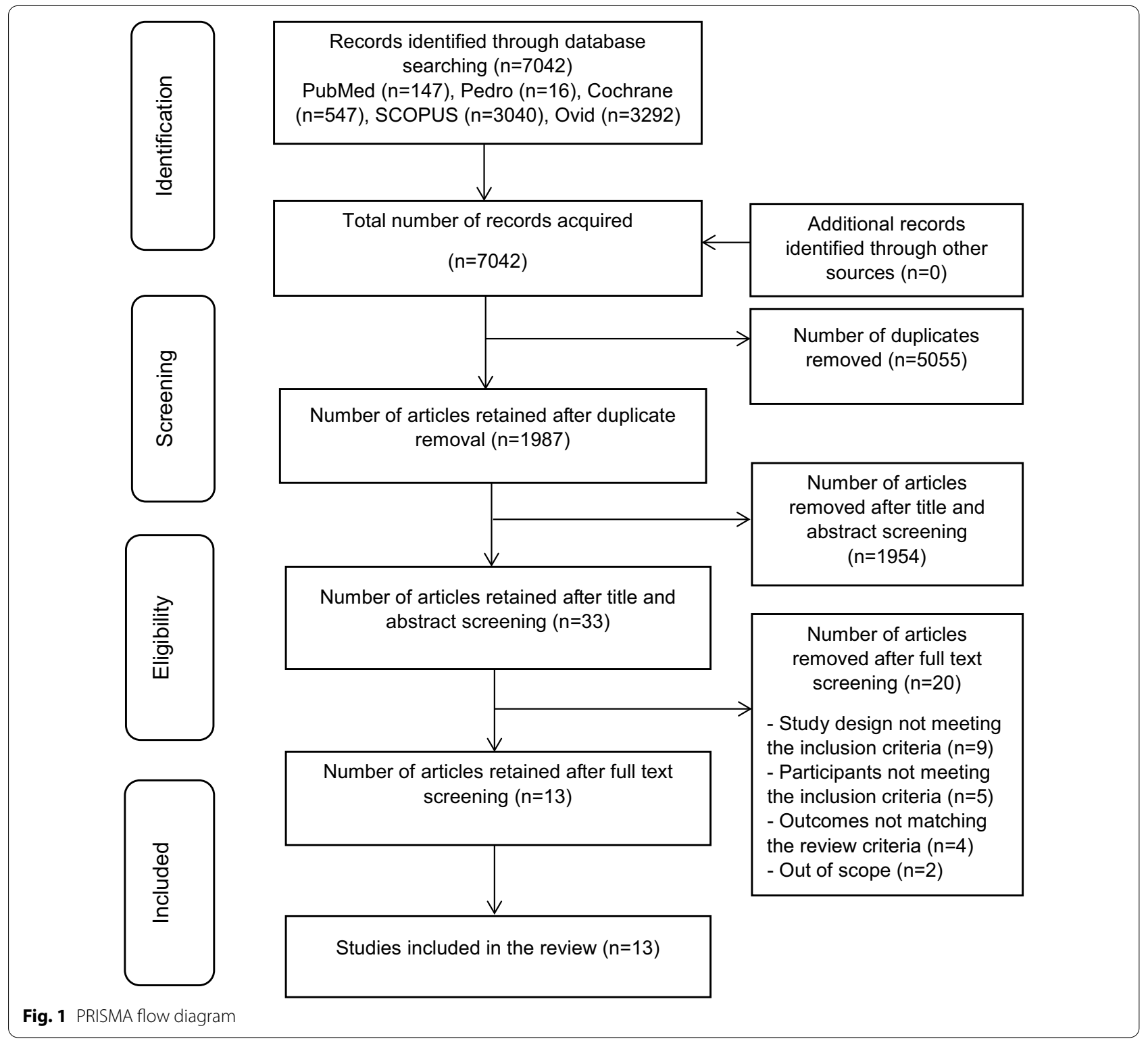

$[28,31]$. The time taken to perform STS is the most frequently assessed outcome of transfer capacity. Eight studies in this review assessed the time taken by individuals with PD to perform the STS transfer and of these seven were considered for the meta-analysis $[9,14,20,22,25$, $27,29]$. One study reported the duration of the movement onset to seat-off phase of the transfer, and hence it was not included in the analysis [11]. We analysed the standardised mean difference values of STS time in individuals with or without PD using a random-effects model. The findings showed that people with PD took a significantly longer time to complete the STS transfer than healthy older adults. The pooled estimate shows that healthy older individuals performed the STS transfer faster by $2.84 \mathrm{~s}$ at $95 \% \mathrm{CI} \pm 1.14$ (SE). Although this finding was statistically significant, it displayed a high heterogeneity $\left[I^{2}=82 \%\right.$; $p$-value $\left.<0.001\right]$ (Fig. 2 ).

\section{Peak joint torque of lower limbs and rate of torque build-up on STS transfer}

Five of the included studies presented an overview of the STS transfer, in terms of the peak torque and rate of torque build-up in people with PD versus healthy controls $[2,9,11,27,29]$. The majority of the studies found that people with PD generated smaller amounts of peak joint torques, and took longer time to attain the peak torques $[11,20,22]$. The standardised mean difference of peak joint torque of the STS was measured in 
Table 1 Participant characteristics

\begin{tabular}{|c|c|c|c|c|c|c|}
\hline \multirow[t]{2}{*}{ Author and year } & \multirow[t]{2}{*}{ Sample size $(N)$} & \multicolumn{5}{|c|}{ Participant determinants } \\
\hline & & $\begin{array}{l}\text { Age (years)- } \\
\text { mean (range) }\end{array}$ & $\begin{array}{l}\text { Hoehn and Yahr } \\
\text { stage }\end{array}$ & UPDRS score & Disease duration & On/off phase \\
\hline Mak et al. (2003) & $\begin{array}{l}(N=13) \text { Controls-6, } \\
\text { PD-7 }\end{array}$ & $\begin{array}{l}\text { Controls - 69.2 } \\
(63-72) \text { PD-66.9 } \\
(53-73)\end{array}$ & Stage $2.5-3$ & - & - & On phase \\
\hline Inkster et al. (2002) & $\begin{array}{l}(N=20) \text { Controls-10, } \\
\text { Men with mild } \\
\text { PD-10 }\end{array}$ & $\begin{array}{l}\text { Controls-65.5 } \\
(53.1-77.9) \\
\text { PD-64.1 (54-74) }\end{array}$ & Stage $1-3$ & $\begin{array}{l}\text { On state }-11 \\
\text { off state }-17.4\end{array}$ & - & On and off phase \\
\hline Pääsuke et al. (2004) & $\begin{array}{l}(N=28) \text { Controls-16, } \\
\text { Females with PD-12 }\end{array}$ & $\begin{array}{l}\text { Controls-71.7 } \\
(66.7-75.5) \\
\text { PD-74.3 } \\
(67.4-81.2)\end{array}$ & Stage $1-3$ & - & $\begin{array}{l}4 \text { to } 18 \text { years, with } \\
\text { a mean of } 10.7(4.5) \\
\text { years }\end{array}$ & On phase \\
\hline Ramsey et al. (2003) & $\begin{array}{l}(N=24) \text { Controls-13, } \\
\text { Men with PD-11 }\end{array}$ & $\begin{array}{l}\text { Controls-73.4 } \\
(66.7-80.1) \text { PD-70 } \\
(62.9-77.5)\end{array}$ & Stage 2 & - & - & On phase \\
\hline Mak et al. (2002) & $\begin{array}{l}(N=40) \text { Controls-20, } \\
\text { PD-20 }\end{array}$ & $\begin{array}{l}\text { Controls-69.3 } \\
(64.2-74.4) \\
\text { PD-65.80 } \\
(58.56-73.04)\end{array}$ & Stage 2-3 & $\begin{array}{l}16.22 \text { to } 30.48 \\
\text { mean score of } 23.35\end{array}$ & $\begin{array}{l}5.68(2.03-9.33) \\
\text { years }\end{array}$ & On phase \\
\hline Bishop et al. (2005) & $(N=41) P D-41$ & PD—66 (50-79) & Stage 1-3 & $\begin{array}{l}\text { Motor subscale part } \\
\text { III, average 4-58 }\end{array}$ & 0.5 to 14 years & On phase \\
\hline Inkster et al. (2004) & $\begin{array}{l}(N=20) \text { Controls-10, } \\
\text { PD-10 }\end{array}$ & $\begin{array}{l}\text { Controls-65.5 } \\
(53.1-77.9) \\
\text { PD—64.1 (54-74.2) }\end{array}$ & Stage 2 & $\begin{array}{l}\text { On state }-11 \\
\text { off state }-17.4\end{array}$ & $\begin{array}{l}2.5 \text { to } 5.5 \text { years, with } \\
\text { a mean of } 4 \text { years }\end{array}$ & On and off phase \\
\hline Buckley et al. (2008) & $\begin{array}{l}(N=24) \text { Controls-12, } \\
\text { PD-12 }\end{array}$ & $\begin{array}{l}\text { Controls -63 } \\
(61-65) \text { PD-63 } \\
(60-66)\end{array}$ & Stage 1-3 & - & $\begin{array}{l}8 \text { to } 14 \text { years, mean } \\
\text { duration of } 11 \text { years }\end{array}$ & On phase \\
\hline Nikfekr et al. (2002) & $\begin{array}{l}(N=13) \text { Controls-7, } \\
\text { PD-6 }\end{array}$ & $\begin{array}{l}\text { Controls - 54 } \\
(45-65) \text { PD-56 } \\
(49-68)\end{array}$ & Stage $1.5-2$ & $\begin{array}{l}\text { Motor sub- } \\
\text { scale-14.6 } \\
\text { range }=13-18\end{array}$ & - & Off phase \\
\hline $\begin{array}{l}\text { De Souza et al. } \\
\text { (2011) }\end{array}$ & $\begin{array}{l}(N=15) \text { Controls-7, } \\
\text { PD-8 }\end{array}$ & $\begin{array}{l}\text { Controls_63.7 } \\
(58.9-68.5) \\
\text { PD-63.8 } \\
(54.3-73.3)\end{array}$ & Stage $2-3$ & - & $7.4(3.9-10.9)$ years & On phase \\
\hline Souza et al. (2018) & $(N=71) P D-71$ & $63.4(50-75)$ & Stage 2-3 & $\begin{array}{l}\text { Motor-section score } \\
6 \text { to } 54 \text { mean }=28.3\end{array}$ & $\begin{array}{l}2 \text { to } 30 \text { years, mean } \\
\text { duration of } 8.7 \text { years }\end{array}$ & Off phase \\
\hline Mak et al. (2004) & $\begin{array}{l}(N=30) \text { Controls-15, } \\
\text { PD-15 }\end{array}$ & $\begin{array}{l}\text { Controls-69.5 } \\
(64.3-74.7) \\
\text { PD-65.5 } \\
(57.6-73.4)\end{array}$ & Stage 2-3 & $\begin{array}{l}16.6 \text { to } 30, \text { mean } \\
\text { score of } 23.2\end{array}$ & - & On phase \\
\hline $\begin{array}{l}\text { Fernandes et al. } \\
\text { (2015) }\end{array}$ & $\begin{array}{l}(N=18) \text { Controls-9, } \\
\text { PD-9 }\end{array}$ & $\begin{array}{l}\text { Con- } \\
\text { trols-63.89 years } \\
(52-80) \text { PD-66 } \\
(52-80)\end{array}$ & Stage 1-2.5 & - & 4.48 to 15.6 years & On phase \\
\hline
\end{tabular}

PD, Parkinson's disease; N, sample size; UPDRS, Unified Parkinson's Disease Rating Scale

Newton metre for four major muscle groups-hip flexors, hip extensors, knee extensors and ankle dorsiflexors (Fig. 3). We found that the maximum hip and knee extension torques generated by the healthy older adults were far greater than individuals with $\mathrm{PD}(p \leq 0.05)$. For the domain of both hip and knee extensor torque; the heterogeneity amongst the papers was very low $\left[I^{2}=0 \%\right.$; $p>0.05]$.

For the domains of hip flexion and ankle dorsiflexion, we analysed the peak joint toques from four contributing studies, three by Mak et al. [11, 27, 29] and one by Inkster et al. [22]. Overall, in both domains our pooled estimate reinforced the fact that the individuals with PD generated lesser amount of hip flexion and ankle dorsiflexion torques compared to healthy older adults during the STS transfer. This overall finding is similar to what three Mak and colleagues' studies [11, 27, 29] showed; however, differs from the findings by Inkster et al. [22]. The heterogeneity was high for hip flexor torque $\left[I^{2}=75 \% ; p=0.02\right]$ and ankle dorsiflexor torque $\left[I^{2}=87 \% ; p=0.83\right]$ (Fig. 3). 


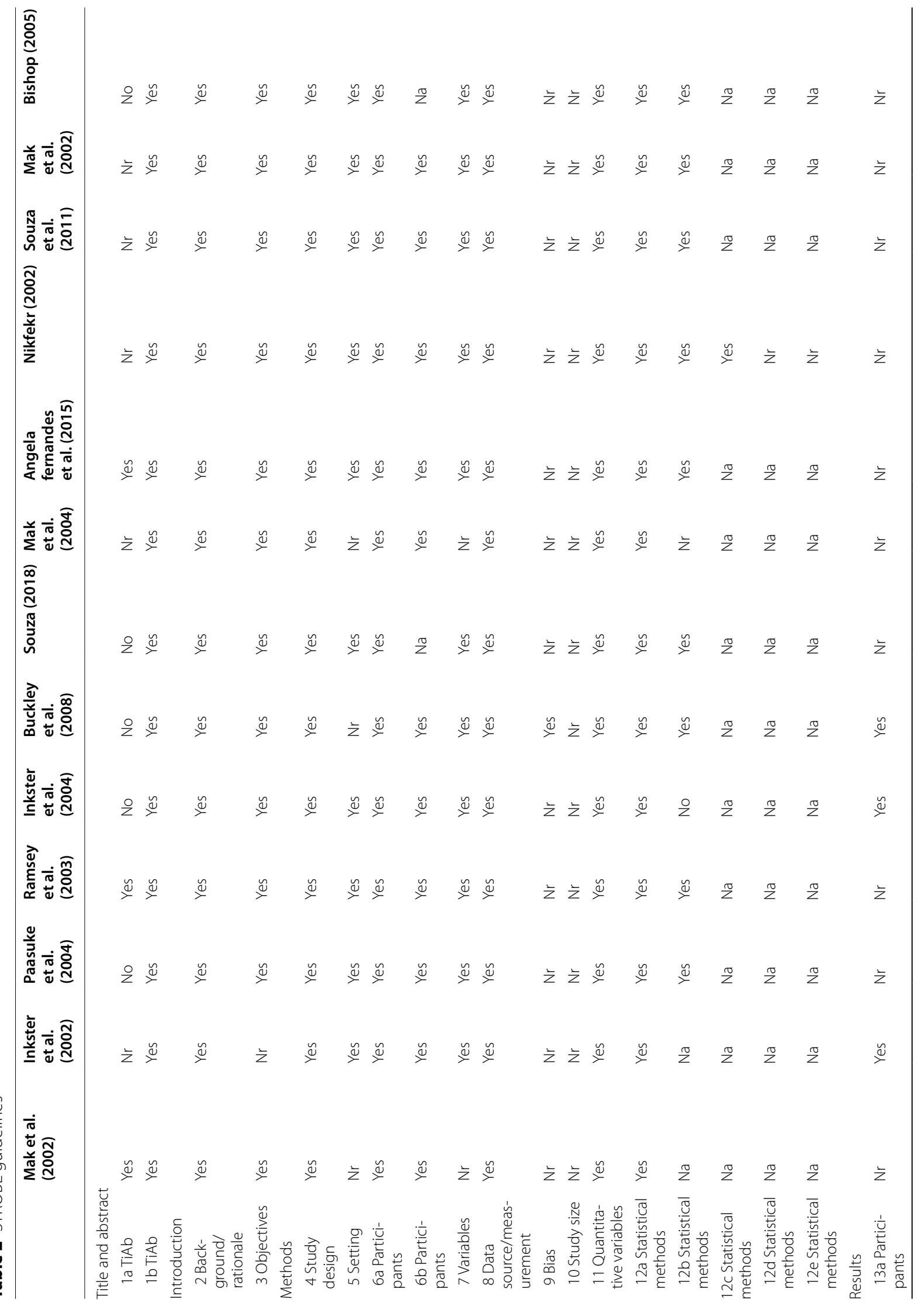




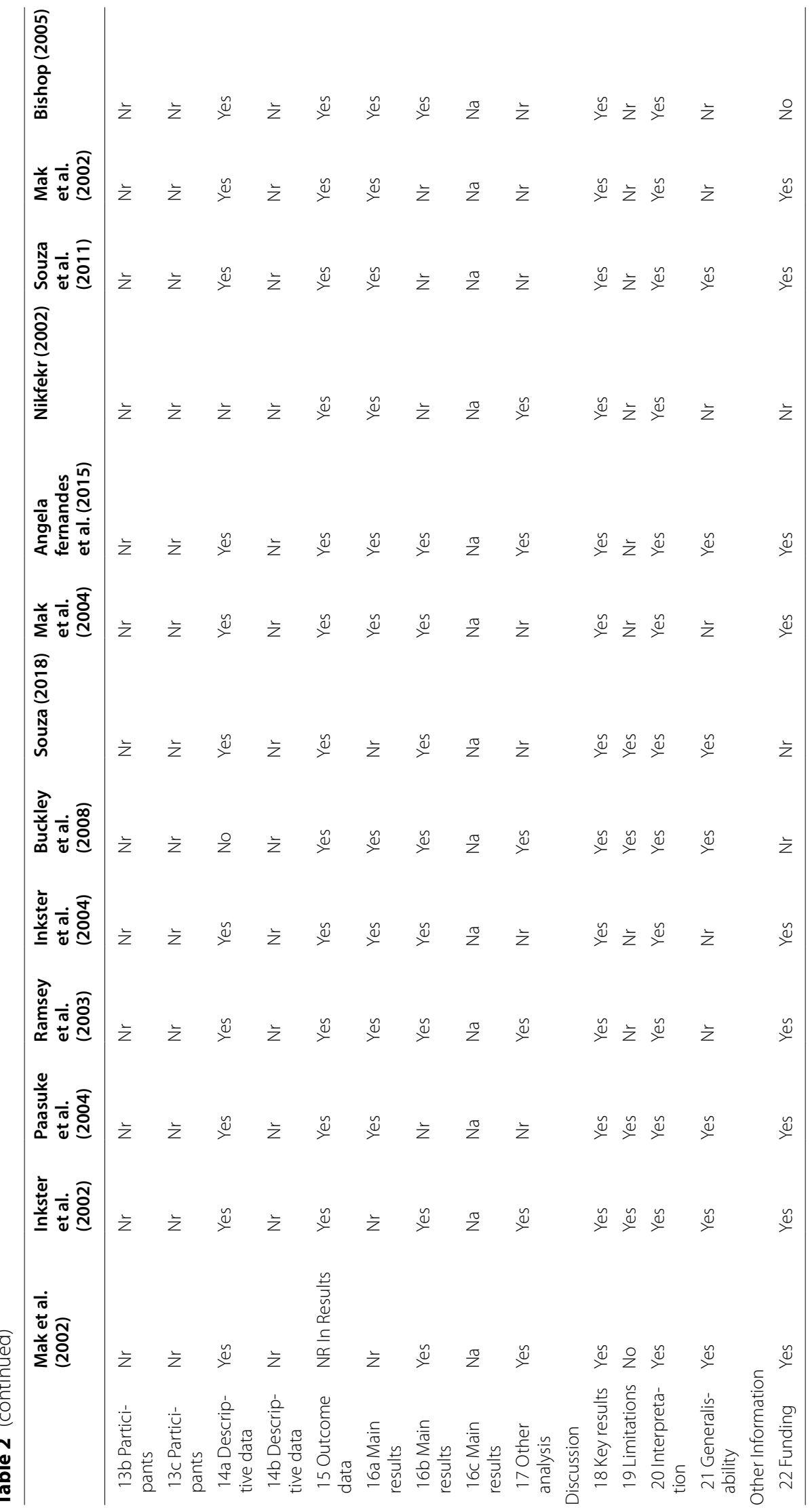




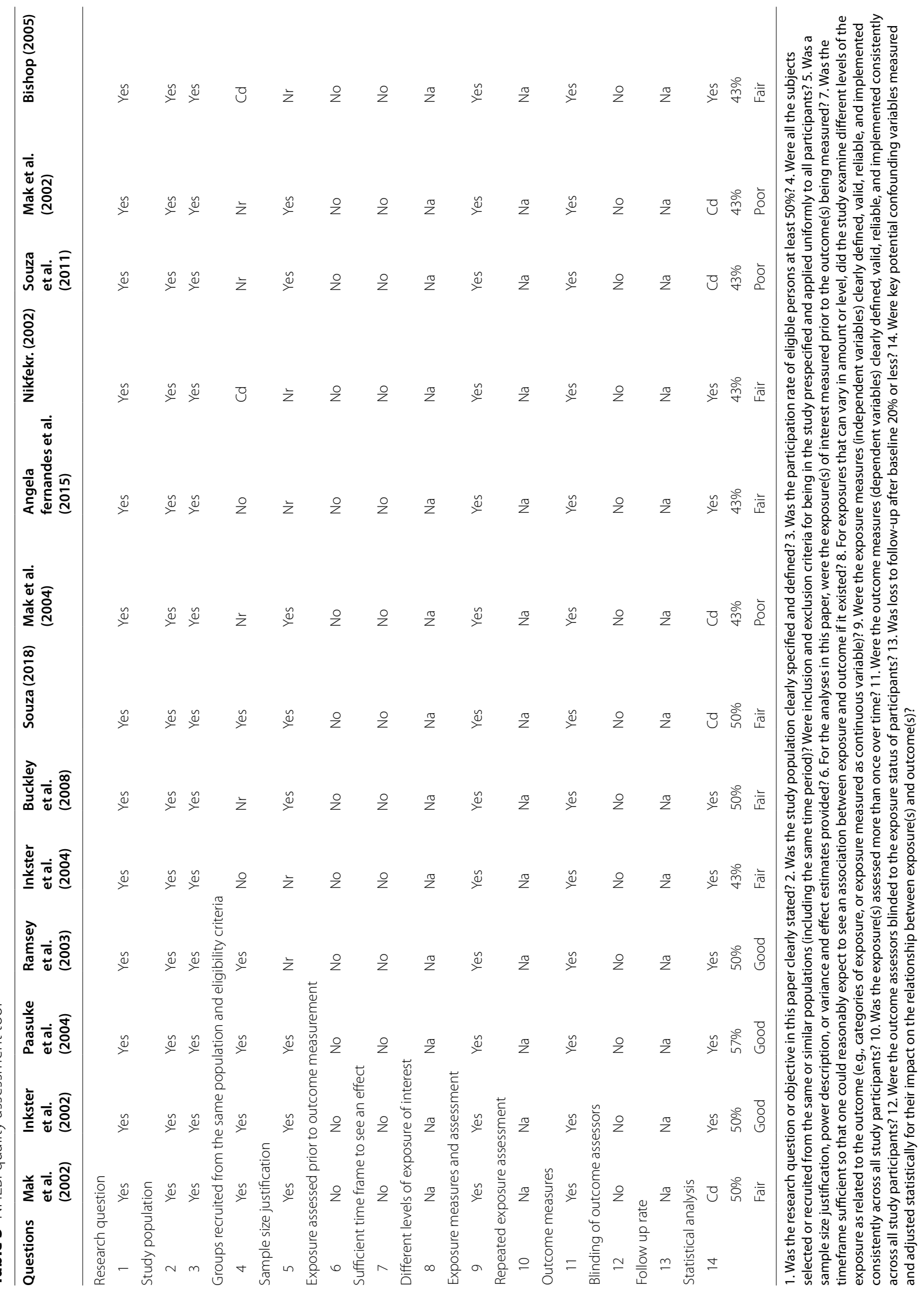


Table 4 Kinetic, kinematic and temporal determinants of sit-to-stand in Parkinson's disease

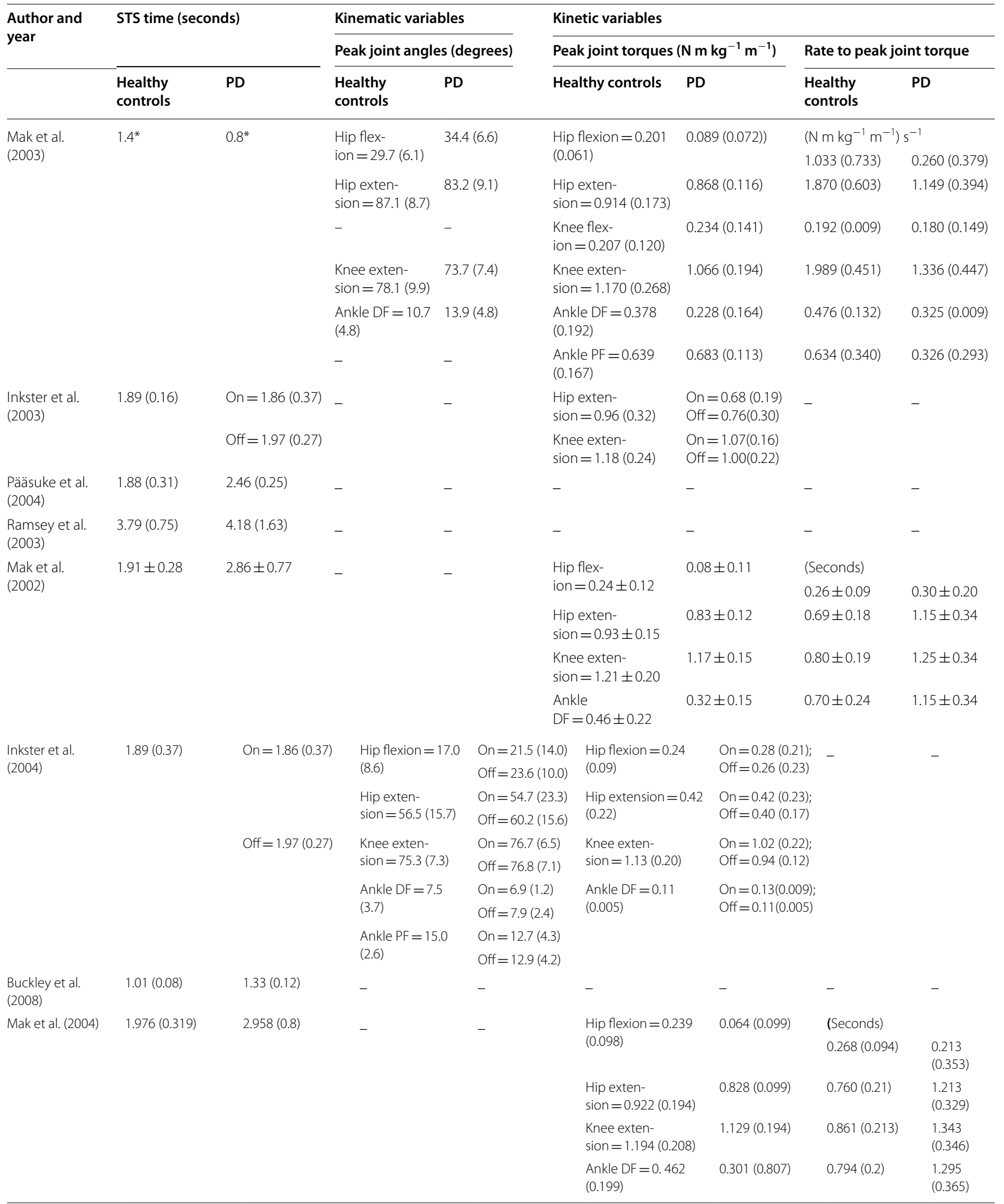




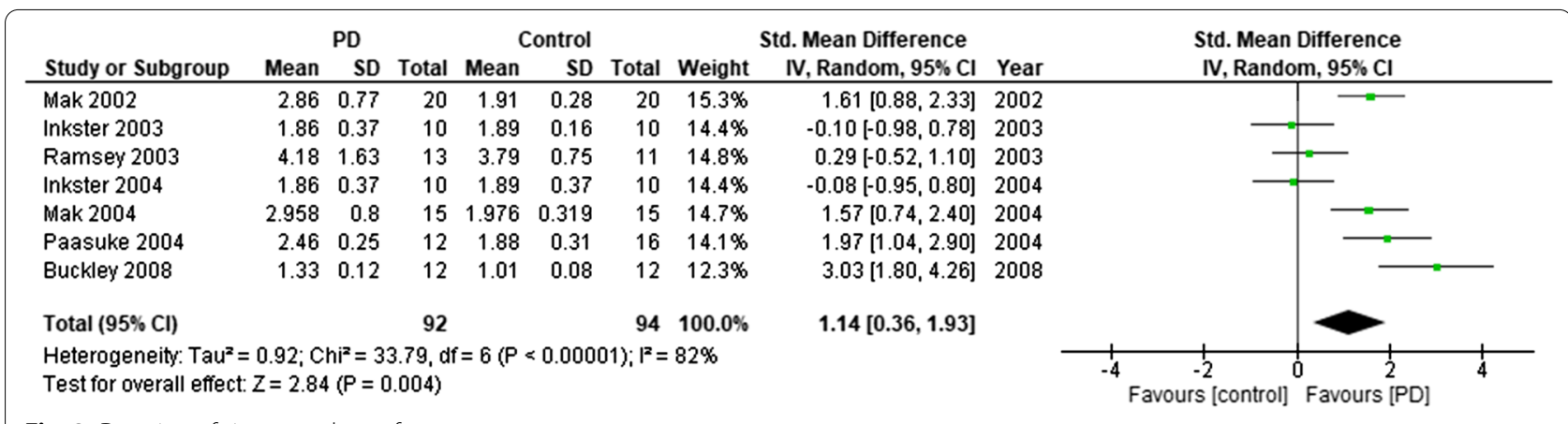

Fig. 2 Duration of sit to stand transfer

Overall weightage of $25.7 \%$ in the Inkster and colleagues' study contributed to the heterogeneity of hip flexor torque. The finding of ankle dorsiflexion torque reported by Inkster et al. was not in line with Mak and colleagues. Inkster et al. [22] reported that the ankle dorsiflexion torque in people with PD was much greater than that in healthy older adults, contributing to $22.5 \%$ weightage of the overall effect measure and large heterogeneity.

The rate of torque build-up data was qualitatively assessed from the three studies [11, 27, 29]. They showed that people with PD reached peak joint torques of lower limbs at slower rates opposed to healthy peers. Additionally, the isometric strength of the hip, knee, and ankle extensors, as well as the ability to produce consistent force are impaired in PD [20]. On the contrary, the electromyographic analysis by Ramsey et al. [14] displayed higher peak amplitude of hip and knee extensor activity in PD. In addition, they also noticed the reduced activity of the ankle dorsiflexors and decreased net ankle-dorsiflexion torque, possibly due to the slower pace of movement transition [14]. The literature from the included studies also demonstrated that the rate at which peak vertical ground-reaction-force, as well as the build-up of horizontal and upward accelerations, are significantly lower in PD [11, 20]. However, the peak vertical groundreaction force per se is not significantly different compared to healthy controls $[11,14,20]$.

\section{Bradykinesia and posture on STS transfer}

Two studies assessed how bradykinesia might potentially contribute to the STS performance in PD [12, 29]. They identified that the altered timing and scaling of muscle recruitment and inefficient switching of the direction of movement are the reasons for generalised movement slowness. Both studies evaluated the transfer during the on-phase, and the combined average time taken to complete the transfer was $1.48(0.476)$ seconds. The flexion momentum phase lasted for $56-64 \%$ of the total transfer time, and the most substantial difference from the peak horizontal velocity phase to seat-off phase was noted between PD and healthy control, contributing to bradykinesia [12, 29].

In this review, two studies assessed the balance performance of people with PD and healthy older adults during the STS transfer in terms of centre of mass displacement $(\mathrm{CoM})$ and centre of pressure interactions. One study evaluated the STS during the on and off phase, whereas the other study assessed it in the off phase $[9,25]$. Inkster et al. [9] recorded the transfer duration, peak joint angles, and torque production along with the CoM displacement. Buckley and colleagues recorded the duration, peak horizontal, and vertical velocity along with the CoM and centre-of-pressure interactions [25]. In PD, the net CoM displacement is significantly larger during horizontal acceleration of the preparatory phase of STS, followed by a lesser displacement in the seat-off phase. On the other hand, in healthy individuals, the CoM displacement during the preparatory phase was similar to that of the seat-off phase [9]. Although the CoM was located posteriorly during the seat off-phase, the required displacement was significantly higher in PD than in healthy individuals. Despite the time taken to perform the STS transfer was prolonged in PD, it was similar between people with mild PD and healthy controls [25]. Two studies evaluated posture and STS transfer during the off phase. When the initial posture was observed during STS, the starting angles of the trunk were similar in people with and without PD, and the final postural angles changed considerably amongst them $[13,28]$. The forward trunk flexion was not only greater at the end of the sequence in the PD group, but also during the entire STS task [28]. The coronal and transverse planar movements of the trunk were less, and it was more in the sagittal plane [13].

\section{Clinical non-motor factors contributing to STS transfer}

Three papers studied how the non-motor domain of cognition, contributed to the STS performance in PD $[21,26,27]$. The dynamic posturography of STS in PD 


\begin{tabular}{|c|c|c|c|c|c|c|c|c|c|c|c|}
\hline \multicolumn{12}{|c|}{ A) Hip flexors } \\
\hline \multirow[b]{2}{*}{ Study or Subgroup } & \multicolumn{3}{|c|}{ PD } & \multicolumn{3}{|c|}{ Control } & \multicolumn{3}{|c|}{ Std. Mean Difference } & \multirow{2}{*}{\multicolumn{2}{|c|}{$\begin{array}{l}\text { Std. Mean Difference } \\
\text { IV, Random, } 95 \% \mathrm{Cl}\end{array}$}} \\
\hline & Mean & SD & Total & Mean & SD & Total & Weight & IV, Random, $95 \% \mathrm{Cl}$ & Year & & \\
\hline Mak 2002 & 0.08 & 0.11 & 20 & 0.24 & 0.12 & 20 & $28.3 \%$ & $-1.36[-2.06,-0.67]$ & 2002 & - & \\
\hline Mak 2003 & 0.089 & 0.072 & 7 & 0.201 & 0.061 & 6 & $19.9 \%$ & $-1.55[-2.85,-0.25]$ & 2003 & & \\
\hline Inkster 2004 & 0.28 & 0.21 & 10 & 0.24 & 0.09 & 10 & $25.7 \%$ & $0.24[-0.64,1.12]$ & 2004 & & \\
\hline Mak 2004 & 0.064 & 0.099 & 15 & 0.239 & 0.098 & 15 & $26.1 \%$ & $-1.73[-2.58,-0.87]$ & 2004 & & \\
\hline & 52 & & & 51 & $100.0 \%$ & $-1.08[-1.98,-0.19]$ & & & \\
\hline \multicolumn{12}{|c|}{ 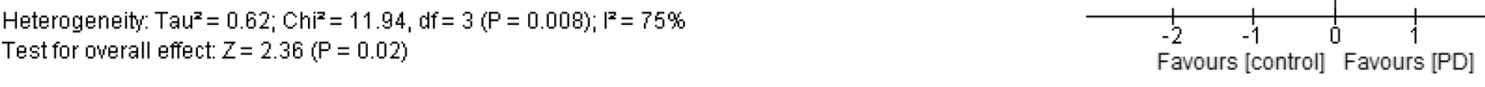 } \\
\hline
\end{tabular}

\section{B) Hip extensors}

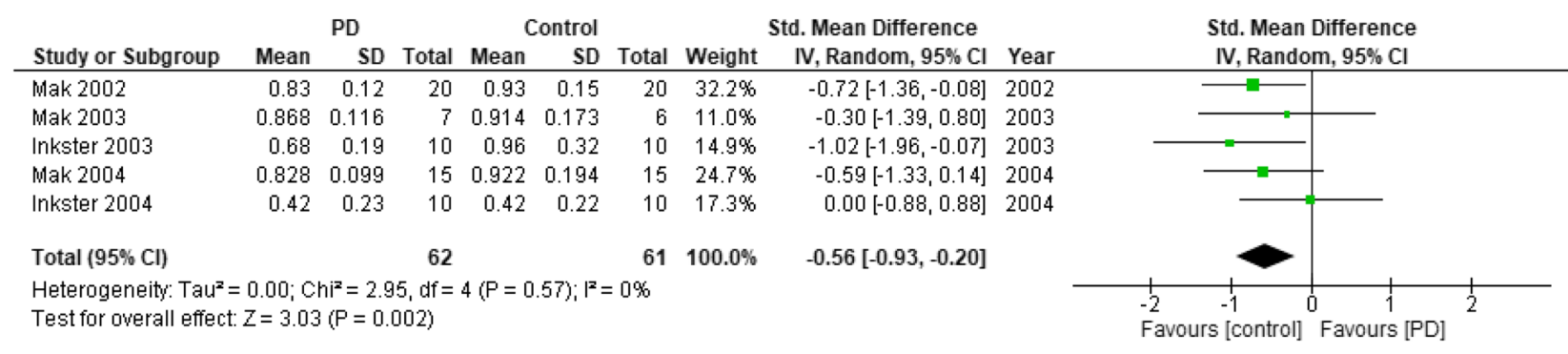

\section{C) Knee extensors}

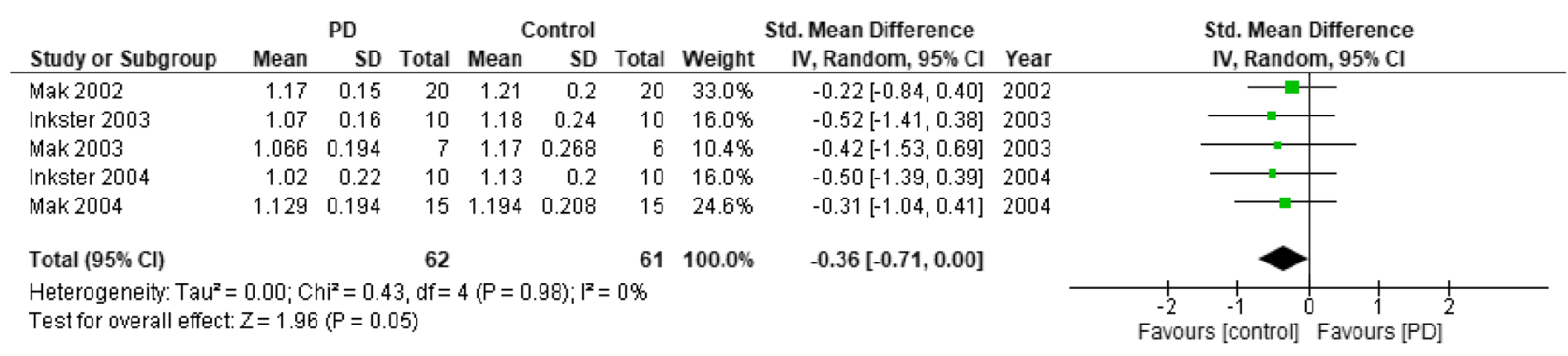

D) Ankle dorsiflexors

\begin{tabular}{|c|c|c|c|c|c|c|c|c|c|c|}
\hline \multirow[b]{2}{*}{ Study or Subgroup } & \multicolumn{3}{|c|}{ PD } & \multicolumn{3}{|c|}{ Control } & \multicolumn{3}{|c|}{ Std. Mean Difference } & \multirow{2}{*}{$\begin{array}{l}\text { Std. Mean Difference } \\
\text { IV, Random, } 95 \% \mathrm{Cl}\end{array}$} \\
\hline & Mean & SD & Total & Mean & SD & Total & Weight & IV, Random, $95 \% \mathrm{Cl}$ & Year & \\
\hline Mak 2002 & 0.32 & 0.15 & 20 & 0.46 & 0.22 & 20 & $27.3 \%$ & $-0.73[-1.37,-0.09]$ & 2002 & -- \\
\hline Mak 2003 & 0.228 & 0.164 & 7 & 0.378 & 0.192 & 6 & $23.4 \%$ & $-0.79[-1.94,0.36]$ & 2003 & -1- \\
\hline Inkster 2004 & 0.13 & 0.009 & 10 & 0.11 & 0.005 & 10 & $22.5 \%$ & $2.63[1.37,3.89]$ & 2004 & \\
\hline Mak 2004 & 0.301 & 0.807 & 15 & 0.462 & 0.199 & 15 & $26.8 \%$ & $-0.27[-0.99,0.45]$ & 2004 & \\
\hline Total $(95 \% \mathrm{Cl})$ & & & 52 & & & 51 & $100.0 \%$ & $0.14[-1.09,1.36]$ & & \\
\hline $\begin{array}{l}\text { Heterogeneity: Tauz } \\
\text { Test for owerall effect }\end{array}$ & $\begin{array}{l}1.33 ; C l \\
Z=0.22\end{array}$ & $\begin{array}{l}h^{2}=22 \\
(P=0 .\end{array}$ & $\begin{array}{l}92, \mathrm{df}= \\
83)\end{array}$ & $=3(P=$ & $0.0001)$ & $i^{2}=8$ & & & & $\begin{array}{cccc}1 & 1 & 1 & 1 \\
-4 & -2 & 0 & 2 \\
\text { Favours [control] } & \text { Favours [PD] }\end{array}$ \\
\hline
\end{tabular}

measured using the balance master system was not positively related to the executive function and semantic verbal fluency examination [21]. Another study assessed how divided attention affects the transfer in two situations-first, the STS task alone, and then along with the Stroop test. Individuals with PD slowed down the STS more under the dual-task conditions compared to controls. The anteroposterior and mediolateral centre-of-pressure displacement was higher in
PD than controls. Nevertheless, the anterior-posterior centre-of-pressure velocity was decreased in PD during the STS task [26]. With an audio-visual cue, the time taken to attain peak joint torque during STS was similar between individuals with and without PD. As the peak vertical and horizontal velocity was decreased, the overall time required for the STS transfer was increased among individuals with PD [27]. 


\section{Discussion}

This study aimed to review various motor and non-motor clinical presentations contributing to the STS transfer in individuals with PD. STS is a functionally important task that involves a complex interplay of all the body segments through the transitional movement of the CoM from a position of more stability to one with less stability $[7,31]$. The STS movement has four phases-the flexion momentum, momentum transfer, extension, and stabilisation phase [21, 31]. For optimal task performance, each joint must move the correct amount, in the right direction, at the appropriate time [31].

\section{Clinical motor factors contributing to STS transfer}

Muscle weakness is prevalent in PD; however, it is unclear whether the weakness is central or peripheral in origin. Disturbed motor planning in the basal ganglia is one of the reasons for weakness and poor motor performance [32]. The strength required through the four phases of STS is discussed in terms of torque generation. Peak hip flexion is attained immediately after forward acceleratory momentum, followed by peak extension torque of hip and knees, and ankle dorsiflexion torque-at seat off. Peak ankle plantarflexion torque is seen towards the termination of the STS transfer [11]. Although the sequence of muscle recruitment is similar for PD and healthy individuals, the peak torque and rate of torque generation at the hip, knee, and ankle is significantly lower in individuals with PD [11, 29].

The reduced rate of force development is related to muscle weakness [33]. Of the three assessed the buildup of joint torques, two studies [27, 29] reported it as the time to reach peak joint torque and one study [11] reported the rate of torque build-up. As the units of measurement were not entirely scalar or vector quantities, we were unable to pool their findings in a metaanalysis. According to Mak and colleagues, the torque build-up was slower in people with PD and the rate to peak torques of hips and knees extension and ankle dorsiflexion were faster by $150 \%$ in normal older adults [11]. Individuals with PD generated insufficient hip flexor and ankle dorsiflexor torques than healthy individuals. Conversely, one study in this review is not in favour of the overall finding, reporting that the hip flexor and ankle dorsiflexor peak joint torque was higher in PD as opposed to age-matched controls [22]. This could be because of the untimely coactivation or overestimation of the antagonist muscular activity during balance reactions [34]. Another probable reason for the discrepancy in the findings could be the level of chronicity and severity of the disease. Mak et al. [11, 27, 29] included individuals with PD staging 1-3 in Hoehn and Yahr grading, whereas Inkster et al. [9] included only individuals with stage 2 in their studies. When compared to healthy adults, Inkster et al. observed that the STS ability in PD was more dependent on the hip strength rather than the knee. A subsequent study also showed a larger displacement of hip flexion in PD than age-matched controls [14]. Therefore, it may be gathered that lesser the isolated hip strength, the slower the performance of the STS transfer with an excessive anterior CoM displacement. Decisively, individuals with PD present variable degrees of muscle deficits, thereby showing considerably different kinematics and rate of force production but retaining the typical sequence of muscle recruitment [11].

Ground reaction forces are measured to evaluate the ability to, and extent of, force exertion and to calculate joint torques [35]. Parameters of the ground-reaction force can accurately reflect the dynamic strength and power of the lower limbs during the STS movement [11, 20]. The lower rate of ground-reaction force development in patients with PD results in the prolonged time period between movement onset and seat-off. This might be attributed to other underlying factors such as bradykinesia, unnecessary coactivation of the antagonists, and possibly rigidity. The deficient tibialis anterior recruitment and co-contraction between the soleus and tibialis anterior are accountable for decreasing the net dorsiflexion torque and the duration of transfer in PD [12, 29]. It is inferred that improving tibialis anterior recruitment might facilitate quicker force production at the ankle during STS. Increased activity of the soleus muscle steadies the anterior rotation of lower leg at the ankle, thus modulating the forward propulsion of the upper torso during the initial phase of STS $[12,29]$.

The transfer is not only prolonged by the ankle strategy, but also by low peak hip flexion torque, longer torque production, and the impaired switching between flexion and extension in lower limbs during STS [29]. The slowness of movements during the acceleration phaseowing to the difficulty in movement initiation-possibly increases the total STS time by up to $60 \%$ [12]. Individuals with PD have trouble switching the direction of the movement during various tasks [29]. While rising from a chair, the delayed termination of the hip flexor activity and the inadequate switch to hip extensor activity results in a prolonged seat-off phase. The initial eccentric hip extensor activity must turn into a concentric one while approaching the limits of stability, thereby increasing the task duration up to $120 \%$. Terminal extension of STS is prolonged by an added $60 \%$ because of slower knee extension-torque development, thus delaying upward acceleration [29]. When the healthy adults simulated the PD individuals' STS speed, the kinematic and kinetic variables were not different, except for a prolonged seat off phase, explaining the difficulty in switching of movement 
direction. Besides reduced torque production, proprioceptive and kinaesthetic deficits in people with PD may also affect postural stability during STS, leading to falls during dual task transferring [29].

While performing the STS transfer, an individual with PD must maintain the CoM within a narrow base of support throughout the vertical acceleration phase for optimal postural stability [9]. Balance control during this dynamic transfer is also associated with the CoM momentum in the horizontal direction. Inkster et al. observed an exaggerated hip flexion strategy in PD to compensate for poor postural control, and to allow the CoM to stay within the base of support; particularly during the preparatory phase of the STS transfer. During STS, the CoM is moved forward by $8 \%$ during the on-phase and 13\% during the off-phase of STS [9]. It is reported in the literature that the upper body's movement is critical in increasing the postural stability during the lift-off phase [11]. Individuals with PD exhibited a higher CoM and centre-of-pressure interaction at seatoff with a delay of almost $1.2 \mathrm{~s}$ from seat-off to full standing. However, their movement pattern was very similar to healthy controls [25]. The individuals with PD demonstrated substantial reductions in the peak horizontal and vertical centre of mass velocity with more CoM displacements towards trunk lateral flexion than the controls. This compensatory mechanism is related to deficient stability and trunk rotation [13, 29].

When an individual with PD gets up from a chair, they display exaggerated trunk flexion as a compensatory postural-stabilisation-strategy which helps them move the CoM and thereby, transit from a three to two points base of support before rising. This is adapted to minimise the period of instability during the transitional phase of the STS sequence. Besides this, they also display a higher angular velocity to generate the required forward momentum in the upper body. The vertical CoM movements at individual trunk sub-segments are not significantly different for people with or without PD suggesting truncal rigidity [13]. A premature coactivation of the extensors and altered hip strategies account for the excessive forward flexion. Although this strategy is essential for enabling the STS task, it results in a more prolonged extension phase of the transfer. While the selection of an appropriate motor program is available among people with $\mathrm{PD}$, the initiation and sequencing of this motor program becomes demanding. Likewise, rapid recruitment of the quadriceps is required to overcome the flexion moment generated by their body weight. As a result, the body tends to fall back into the chair as they begin to rise [28]. This commonly adopted compensatory mechanism shifts the CoM anteriorly up to the limits of stability by generating a higher degree of trunk inclination, thus aiding the STS transfer [13]. Bradykinesia occurs due to the failure of the basal ganglia to reinforce the cortical mechanisms through motor planning and execution. In people with bradykinesia, the muscle recruitment is welltimed, but the scaling is subpar. The midline motor area is most affected, impacting the pace of movements and delaying reaction times [36]. The basal ganglia withhold motor responses until the appropriate time for its firing, while its affection might show asynchronous muscle activation [37]. People with PD show alternating bursts of muscle activity between the tibialis anterior and soleus before the initiation of STS [12]. This premature firing describes an inability to generate enough muscle force with the initial activation of the tibialis anterior; therefore, subsequent bursts of activity are required to create the movement pattern.

\section{Clinical non-motor factors contributing to STS transfer}

The non-motor domain of executive function involves the processing of internal and external stimuli, planning and problem solving, multitasking, initiation, and termination of activities and abstract thinking. Lesions in the basal ganglia affect sensory scaling and sensorimotor integration that indirectly affect this higher-order functioning and lead to movement planning and processing deficits [37]. Those with intact motor planning and sequencing have a higher risk of falls and functional dependency [36]. As the disease chronicity advances, a decline in cognitive-motor interplay along with the other motor deficits appears. Performing the STS transfer with a cognitive task makes it challenging and time-consuming for individuals with PD. Reduced anticipatory postural adjustments are compromised in an effort to focus on the cognitive task at hand, thus making the transfer daunting [26]. The cognitive-motor interplay defect allows poor selection of motor responses based on the available sensory stimuli reaching the basal ganglia [36]. This absence of internal cues causes difficulty in stringing together multiple components of a movement sequence. The switch from flexion to extension during STS is particularly tricky in PD, and external cues are known to enhance this switch in direction. Audio-visual cues improve the attention capacity in $\mathrm{PD}$, thus enhancing the preparatory motor phase of STS [26]. Additionally, an overactive lateral premotor area compensates for the deficits in the basal ganglia. Providing sensory cues during the STS task, facilitates this compensation and improves the speed of performance [36]. Experts showed that audio-visual cues in PD shall improve the initiation and execution of STS by facilitating motor planning [38]. The improved generation of peak joint torques, especially the markedly reduced hip flexion torque, could also be the result of a heightened attention level in patients as part of motor preparation. 


\section{Strength and limitations of this systematic review}

The domains in which research was available were strength, bradykinesia, balance, posture, and cognition. This review took into account the studies that objectively evaluated the STS transfer based on the kinematic and kinetic variables such as, magnitude and rate of joint torque production, the velocity of the CoM, peak vertical ground-reaction force, and CoM and centre-of-pressure interaction.

The main limitation of this systematic review was that most of the included studies provided lab-based, posturographic, and isokinetic analysis, but did not include conventional clinical assessments. Therefore, from a clinical perspective, this review provides a narrow understanding of the extent to which a given factor affects the STS transfer in individuals with PD. Another potential limitation was that the contributing elements of STS were not studied through individual stages of the PD, but holistically reported through 1-3 stages of the disease.

\section{Future implication}

Individuals with PD find it difficult switching the movement direction, less torque generation rate during STS transfer and more postural instability at the seat-off phase. The disease chronicity also affects their executive functioning predisposing them to a higher risk of falls when the STS is performed with cognitive dual task. Future studies must explore these dimensions.

\section{Conclusion}

Individuals with PD have a similar sequence of muscle activation as healthy individuals, but with a reduced torque generation rate. They use compensatory postural strategies to maintain their balance during the STS transfer; however, they demonstrate postural instability during the seat off phase. Furthermore, the switching of movement direction becomes difficult in addition to poor torque generation. The clinical relevance of this systematic review is that assessment of lower limb muscles torque, movement direction switching and cognitive dual task should be considered during STS, warranting appropriate rehabilitation strategies for postural stability of STS of individuals with PD.

\section{Abbreviations}

PD: Parkinson's disease; STS: Sit to stand; UPDRS: Unified Parkinson's Disease Rating Scale; COM: Centre of mass; STROBE: Strengthening the reporting of observational studies in epidemiology; NHLBI: National Heart, Lung, and Blood Institute; 95\% Cl: 95\% Confidence interval.

\section{Supplementary Information}

The online version contains supplementary material available at https://doi. org/10.1186/s41983-021-00396-z.

Additional file 1: Search strategy.

\section{Acknowledgements}

We thank DrVasudeva Guddattu, Associate Professor, Department of data science, Prasanna School of Public Health, Manipal Academy of Higher Education, for his contribution in the statistical analysis.

\section{Authors' contributions}

CPDC, PTR and SK conceived the original idea, collected data and wrote the manuscript. All authors read and approved the final manuscript.

\section{Funding}

No funding has been received for this project.

Availability of data and materials

All data generated or analysed during this study are included in this published article [and its Additional file 1].

\section{Declarations}

Ethics approval and consent to participate

Not applicable.

Consent for publication

Not applicable.

\section{Competing interests}

The authors declare that they have no competing interests.

Received: 2 July 2021 Accepted: 11 October 2021

Published online: 30 October 2021

References

1. Galvan A, Wichmann T. Pathophysiology of Parkinsonism. Clin Neurophysiol. 2008;119:1459-74. https://doi.org/10.1016/j.clinph.2008.03.017.

2. Raza C, Anjum R, Shakeel NUA. Parkinson's disease: mechanisms, translational models and management strategies. Life Sci. 2019;226:77-90. https://doi.org/10.1016/j.lfs.2019.03.057.

3. Tysnes OB, Storstein A. Epidemiology of Parkinson's disease diagnosis of PD. J Neural Transm (Vienna). 2017;124(8):901-5. https://doi.org/10.1007/ s00702-017-1686-y.

4. Garcia Ruiz PJ, Catalán MJ, Fernández Carril JM. Initial motor symptoms of Parkinson disease. Neurologist. 2011;17(6):S18-20. https://doi.org/10. 1097/nrl.0b013e31823966b4.

5. Lee HM, Koh S-B. Many faces of Parkinson's disease: non-motor symptoms of Parkinson's disease. Mov Disord. 2015;8(2):92-7. https://doi.org/10. 14802/jmd.15003.

6. Jankovic J. Parkinson's disease: clinical features and diagnosis. J Neurol Neurosurg Psychiatry. 2008;79(4):368-76. https://doi.org/10.1136/jnnp. 2007.131045.

7. Bhatt T, Yang F, Mak MKY, Hui-Chan CWY, Pai YC. Effect of externally cued training on dynamic stability control during the sit-to-stand task in people with Parkinson disease. Phys Ther. 2013;93(4):492-503. https://doi. org/10.2522/ptj.20100423.

8. Rodriguez-Oroz MC, Jahanshahi M, Krack P, Litvan I, Macias R, Bezard E, et al. Initial clinical manifestations of Parkinson's disease: features and pathophysiological mechanisms. Lancet Neurol. 2009;8(12):1128-39. https://doi.org/10.1016/s1474-4422(09)70293-5. 
9. Inkster LM, Eng JJ. Postural control during a sit-to-stand task in individuals with mild Parkinson's disease. Exp Brain Res. 2004;154(1):33-8. https://doi. org/10.1007/s00221-003-1629-8.

10. Greve C, Zijlstra W, Hortobágyi T, Bongers RM. Not all is lost: old adults retain flexibility in motor behaviour during sit-to-stand. PLOS ONE. 2013;8(10): e77760. https://doi.org/10.1371/journal.pone.0077760

11. Mak MKY, Levin O, Mizrahi J, Hui-Chan CWY. Joint torques during sitto-stand in healthy subjects and people with Parkinson's disease. Clin Biomech (Bristol, Avon). 2003;18(3):197-206. https://doi.org/10.1016/ s0268-0033(02)00191-2

12. Bishop M, Brunt D, Pathare N, Ko M, Marjama-Lyons J. Changes in distal muscle timing may contribute to slowness during sit to stand in Parkinson's disease. Clin Biomech. 2005;20(1):112-7. https://doi.org/10.1016/j. clinbiomech.2004.08.002.

13. Nikfekr E, Kerr K, Attfield S, Playford DE. Trunk movement in Parkinson's disease during rising from seated position. Mov Disord. 2002;17(2):27482. https://doi.org/10.1002/mds.10073.

14. Ramsey VK, Miszko TA, Horvat M. Muscle activation and force production in Parkinson's patients during sit to stand transfers. Clin Biomech. 2004:19(4):377-84. https://doi.org/10.1016/j.clinbiomech.2003.08.004

15. Gago MF, Garrett MC, Fonseca MR, Rosas MJ, Simões MF, Vieira S, et al. How do cognitive and axial motor signs correlate in Parkinson's disease? A 6-year prospective study. J Neurol. 2009;256(10):1655-62. https://doi. org/10.1007/s00415-009-5174-7.

16. Higginson $\mathrm{Cl}$, Lanni K, Sigvardt KA, Disbrow EA. The contribution of trail making to the prediction of performance-based instrumental activities of daily living in Parkinson's disease without dementia. J Clin Exp Neuropsychol. 2013;35(5):530-9. https://doi.org/10.1080/13803395.2013.798397.

17. Smulders K, van Nimwegen M, Munneke M, Bloem BR, Kessels RPC, Esselink RAJ. Involvement of specific executive functions in mobility in Parkinson's disease. Parkinsonism Relat Disord. 2013;19(1):126-8. https:// doi.org/10.1016/j.parkreldis.2012.06.010.

18. Marchese R, Bove M, Abbruzzese G. Effect of cognitive and motor tasks on postural stability in Parkinson's disease: a posturographic study. Mov Disord. 2003;18(6):652-8. https://doi.org/10.1002/mds.10418.

19. Bryant MS, Kang GE, Protas EJ. Relation of chair rising ability to activities of daily living and physical activity in Parkinson's disease. Arch Physiother. 2020. https://doi.org/10.1186/s40945-020-00094-8.

20. Pääsuke M, Ereline J, Gapeyeva H, Joost K, Mõttus K, Taba P. Leg-extension strength and chair-rise performance in elderly women with Parkinson's disease. J Aging Phys Act. 2004;12(4):511-24. https://doi.org/10.1123/ japa.12.4.511.

21. de Souza CO, Voos MC, Barbosa AF, Chen J, Francato DCV, Milosevic M, et al. Relationship between posturography, clinical balance and executive function in Parkinson's disease. J Mot Behav. 2019;51(2):212-21. https:// doi.org/10.1080/00222895.2018.1458279.

22. Inkster LM, Eng JJ, MacIntyre DL, Jon SA. Leg muscle strength is reduced in Parkinson's disease and relates to the ability to rise from a chair. Mov Disord. 2003;18(2):157-62. https://doi.org/10.1002/mds.10299.

23. von Elm E, Altman DG, Egger M, Pocock SJ, Gøtzsche PC, Vandenbroucke JP, STROBE Initiative. The Strengthening the Reporting of Observational Studies in Epidemiology (STROBE) Statement: guidelines for reporting observational studies. Int J Surg. 2014;12(12):1495-9. https://doi.org/10. 1016/j.jjsu.2014.07.013.

24. National Heart, Lung, and Blood Institute. Study Quality Assessment Tools; 2019. https://www.nhlbi.nih.gov/health-topics/study-quality-asses sment-tools.
25. Buckley TA, Pitsikoulis C, Hass CJ. Dynamic postural stability during sit-to-walk transitions in Parkinson disease patients. Mov Disord. 2008;23(9):1274-80. https://doi.org/10.1002/mds.22079.

26. Fernandes Â, Sousa ASP, Couras J, Rocha N, Tavares JMRS. Influence of dual-task on sit-to-stand-to-sit postural control in Parkinson's disease. Med Eng Phys. 2015;37(11):1070-5. https://doi.org/10.1016/j.medengphy. 2015.08.011.

27. Mak MK, Hui-chan CW. Audiovisual cues can enhance sit-to-stand in patients with Parkinson's disease. Mov Disord. 2004;19(9):1012-9. https:// doi.org/10.1002/mds.20196.

28. Aparecida L, Sande P, Souza D, de Biagi M, Mukherjee M, Carlos V. The effect of the partially restricted sit-to-stand task on biomechanical variables in subjects with and without Parkinson's disease. J Electromyogr Kinesiol. 2011;21(5):719-26. https://doi.org/10.1016/j.jelekin.2011.04.007.

29. Mak MKY, Hui-Chan CWY. Switching of movement direction is central to Parkinsonian bradykinesia in sit-to-stand. Mov Disord. 2002;17(6):118895. https://doi.org/10.1002/mds.10257.

30. Vandenbroucke JP, von Elm E, Altman DG, Gøtzsche PC, Mulrow CD, Pocock SJ, et al. Strengthening the reporting of observational studies in epidemiology (STROBE): explanation and elaboration. PLOS Med. 2007;4(10): e297. https://doi.org/10.1371/journal.pmed.0040297.

31. Fotoohabadi MR, Tully EA, Galea MP. Kinematics of rising from a chair: image-based analysis of the sagittal hip-spine movement pattern in elderly people who are healthy. Phys Ther. 2010;90(4):561-71. https://doi. org/10.2522/ptj.20090093.

32. Cano-De-La-Cuerda R, Pérez-De-Heredia M, Miangolarra-Page JC, MuñozHellín E, Fernández-De-Las-Peñas C. Is there muscular weakness in parkinson's disease? Am J Phys Med Rehabil. 2010;89(1):70-6. https://doi. org/10.1097/phm.0b013e3181a9ed9b.

33. Corcos DM, Chen CM, Quinn NP, McAuley J, Rothwell JC. Strength in Parkinson's disease: relationship to rate of force generation and clinical status. Ann Neurol. 1996;39(1):79-88. https://doi.org/10.1002/ana.41039 0112.

34. Lang KC, Hackney ME, Ting LH, McKay JL. Antagonist muscle activity during reactive balance responses is elevated in Parkinson's disease and in balance impairment. PLoS ONE. 2019;14(1): e0211137. https://doi.org/10. 1371/journal.pone.0211137.

35. Tsuji T, Tsunoda K, Mitsuishi Y, Okura T. Ground reaction force in sit-tostand movement reflects lower limb muscle strength and power in community-dwelling older ddults. Int J Gerontol. 2015;9(2):111-8. https:// doi.org/10.1016/j.ijge.2015.05.009

36. Berardelli A, Rothwell JC, Thompson PD, Hallett M. Pathophysiology of bradykinesia in Parkinson's disease. Brain. 2001;124(11):2131-46. https:// doi.org/10.1093/brain/124.11.2131.

37. Bastin J, Polosan M, Benis D, Goetz L, Bhattacharjee M, Piallat B, et al. Inhibitory control and error monitoring by human subthalamic neurons. Transl Psychiatry. 2014;4(9):2-9. https://doi.org/10.1038/tp.2014.73.

38. van Wegen EEH, Hirsch MA, Huiskamp M, Kwakkel G. Harnessing cueing training for neuroplasticity in Parkinson disease. Top Geriatric Rehabili. 2014;30(1):46-57. https://doi.org/10.1097/TGR.0000000000000005.

\section{Publisher's Note}

Springer Nature remains neutral with regard to jurisdictional claims in published maps and institutional affiliations. 